\title{
Scholarship Skill Set for Developing Economies: A Model for 21st Century Postgraduate Researchers in Pakistan
}

\author{
Muneeba Haroon \\ Syed Zeeshan Arshad
}

\begin{abstract}
The purpose of this report is to identify the research skills that are required to conduct constructive and meaningful research and propose a 21st century scholarship skill-set for postgraduate researchers from development economies. Argumentative analysis of relevant published material and selective interviews, based on the Delphi technique, have been used to assess the need and importance of developing such a skill-set. The problems faced by a local postgraduate researcher, that were identified, include limited access to content, resistance towards digital age, absence of peer and ethical review groups, absence of links between academia and industry, lack of infrastructure, weak drafting skills, and an inflexible curriculum.
\end{abstract}

The proposed scholarship skill-set for a postgraduate researcher from developing economies consists of the following broad categories: basic skills, discipline skills, research management skills, information technology (IT) skills, collaboration skills, and research literacy and processing skills. Under each of these broadly defined skills, four skill subsets or sub-skills have been identified, which make up the skill category. Apart from extrapolating the scholarship skill-set, we also conclude that all stakeholders in a research process are equally responsible for ensuring that research processes are effective, constructive, and produce new knowledge. All stakeholders, therefore, need to contribute in the reformation and development of our educational infrastructure, especially at the postgraduate level.

Keywords: Basic skills, collaboration skills, discipline skills, existence skills, information technology skills, postgraduate researcher, research literacy and processing skills, research management skills, scholarship, and scholarship skill-set.

\section{Introduction}

Research and scholarship, likes other walks of life, has significantly been affected by globalization. Borgman (2007), in her book 'Scholarship in the Digital Age: Information, Infrastructure and the Internet', describes how research and scholarly activities have been influenced by information technology. Borgman, in her book, has also identified the advantages and disadvantages of this change in the academic environment.

The digital age and computer-based technology have changed the way academia is organized, financed and governed. They have dramatically altered lifestyles, and have

Muneeba Haroon is a Research Consultant at SZABIST, Muneeba00_01@yahoo.com Syed Zeeshan Arshad is an Assistant Professor at SZABIST, Zeeshan@szabist.edu.pk 
brought with them efficiency, speed, low procurement cost, and the ability to multitask with great accuracy. According to the National Research Council Staff (2005), our society is now being reshaped by rapid advances in information technologies, such as computers, telecommunications networks, and other digital systems that have vastly increased our capacity to know, achieve, and collaborate. Rapid evolution of digital technologies is also creating new opportunities for our researchers and scholars. A scholar in the digital age needs access to a bulk of research material and journals that are either available online freely or at an affordable cost. Although all the literature available online is unverifiable and may lack credibility, lack of access to them and their unavailability would deprive researchers of an important source of information, discussions, and perspectives. Universities and their stakeholders, therefore, need to develop a continuing dialogue with national and grass roots components to help research institutions broaden the horizon of higher-education enterprises.

In order to create a link between academia and industry, build research capacity, and bring researchers and scholarship in developing economies at par with their counterparts in developed economies, a scholarship skill-set that incorporates the expectations and demands of contemporary research, needs to be developed for postgraduate students and researchers. This study, therefore, focuses on analyzing and developing a skill-set that would be conducive to developing research capacity in developing economies. Argumentative analysis of relevant published material and selective interviews, based on the Delphi technique, have been used to assess the need and importance of developing such a skill-set. For the purpose of validation, the triangulation method has been used. Semi-structured interviews were conducted from pre-identified Pakistani MS and PhD. scholars (holding local / foreign degrees), research consultants, and people associated with academia and the industry. During the course of the research, several time constraints were faced which limited the scope of research. There were several sampling restrictions as the sample was selected on the basis of convenience. The biggest limitation of the research proved to be the unavailability of literature on the educational system of Pakistan.

\section{Research Findings}

The problems faced by researchers in developing economies include the following: lack of access to and unavailability of content and literature (Manzoor, November 17, 2008), resistance towards the digital age and reluctance in adopting advanced technologies (Halepoto, November 12, 2008), absence of peer and ethical review groups (Dr. Nadeem, November 4, 2008), disconnect between academia and industry (Effendi, November 17, 2008), missing information infrastructure for scholarship (Ali November 14, 2008), weak drafting skills (Nawab, November 17, 2008), and an inflexible curriculum (Dr. Zaki, November 15, 2008). Since in developing countries, people associated with scholarship, academia, research and postgraduate studies cannot depend on research alone as a source of living, motivating people is yet another problem (Hidi and Harackiewicz, 2000). The task of research per se, combined with the above-mentioned constraints, can make the research process overwhelming and intimidating for a research student, resulting in either the researcher coming up with sub-standard quality work or distancing 
himself/herself from the research task completely. At times, some of the brightest scholars and researchers end up dropping out of their research and degree programs due to the inability to cope with the pressure of what Schwartz (2008) believes to be researchers' tendency to feel incompetent. A weak understanding of the English language, which happens to be the default language of research, also hampers the quality of research (Rahman, 2004). The inability to think in English and the process of translating ideas and thoughts from one language to another also affect the flow of written research papers and reports.

Lack of access to literature and lack of information about the availability of funds also restrict the scope of research. It can also result in the researcher misrepresenting data in a desperate attempt to get hold of funds for the proposed research. Deficiency of collaborative networks and lack of connections with international academic researchers, scholars and people associated with scholarship, weakens peer and ethical review of research publications. Data validation and research ethics again are areas that are weak due to limited resources. Hence, there seems to be a tremendous room for improvement in the educational sector at the postgraduate level.

\section{Critical Assessments of Research Findings}

Although the lack of access to content is a huge barrier for local researchers and scholars, the positive role played by the Higher Education Commission (HEC) of Pakistan cannot be overlooked or ignored. The HEC has setup a digital library for the facilitation of local scholars and researchers, but the accessibility is restricted to the postgraduate students and scholars of public universities. The private universities, on the other hand, because of their profit maximization motive, hinder the growth of postgraduate researchers by using cost cutting techniques. The HEC has also tried to decrease the digital divide between the scholars from developing and developed nations by equipping private and public universities with computing and internet-based facilities. The HEC has also incorporated computing and technology studies at the high school and undergraduate level in order to support the researchers at the postgraduate level.

\section{Scholarship Skill Set for a Postgraduate Researcher in Pakistan}

The proposed skill set for a postgraduate researcher in developing economies such as Pakistan can be broadly categorized into the following skills: basic skills, discipline skills, research management skills, information technology (IT) skills, collaboration skills, and research literacy and processing skills.

Basic and discipline skills together are referred to as existence skills because of the view that local postgraduate students cannot survive as researchers without being able to identify problems, comprehend situations, and utilizing resources effectively and efficiently. Students can also be equipped and trained to be researchers in a considerably shorter span of time if they develop and nurture their existence skills. 


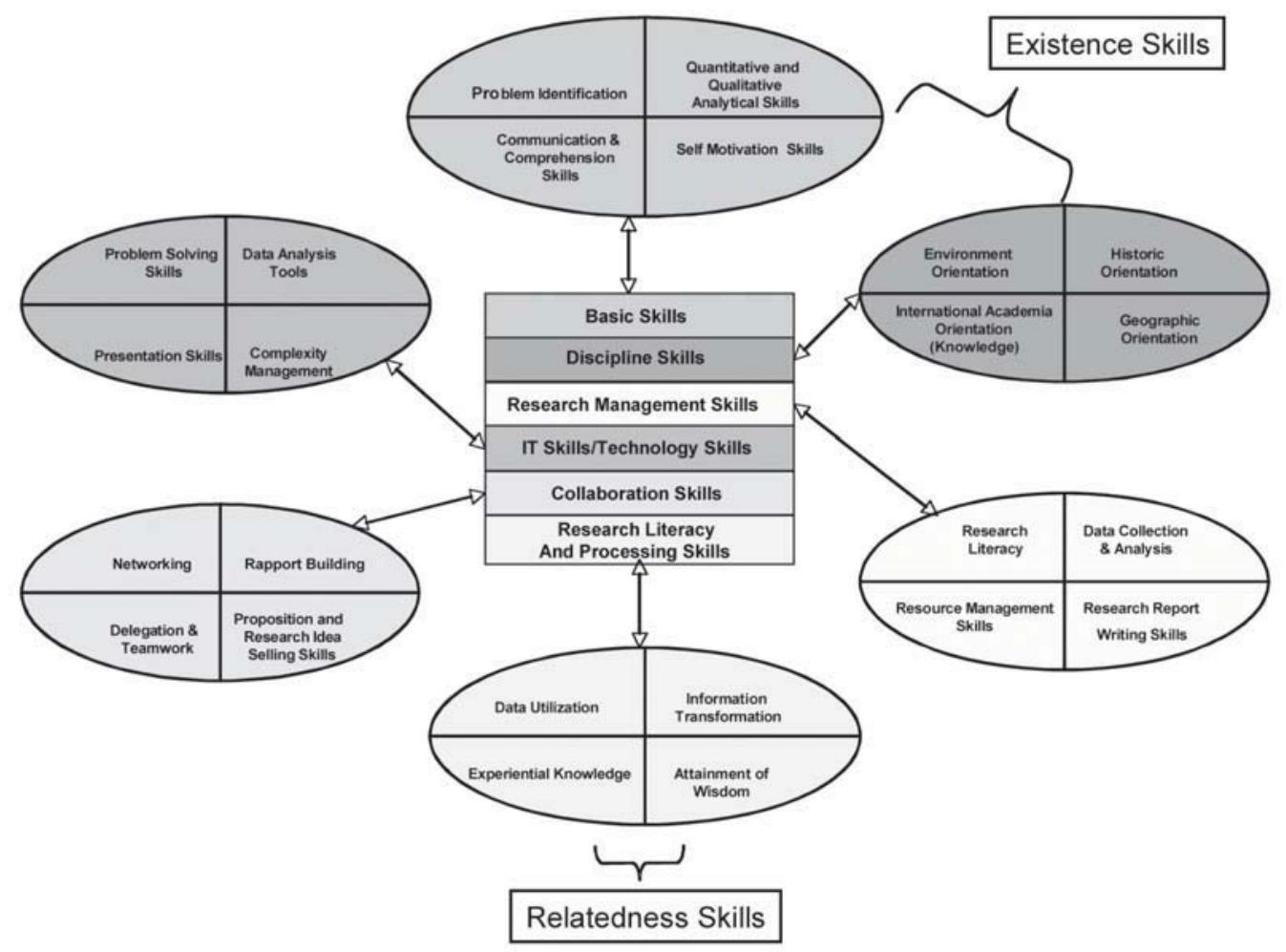

The basic skills that any researcher needs to acquire are problem identification and comprehension skills, communication skills (both written and oral), the ability to academically motivate ones own self, and quantitative and qualitative analytical skills. Discipline Skills would obligate postgraduate research students to gain some degree of what is often referred to as "cultural literacy" (Johnson, 2005). Cultural Literacy will help provide a base of knowledge in history, social science, science, literature, and both physical and cultural geography. According to the American Library Association, research literacy refers to a person's ability to gauge and recognize when the information is needed, whereas simultaneously having the ability to locate, evaluate, and use effectively the needed information. Information literacy skills would include data utilization skills, the ability of transforming data into information, information to knowledge, and knowledge to wisdom.

Research management broadly covers time management skills, managing relationships with supervisors, subordinates, and peers, maximizing impact, managing within the funding available. Furthermore, researchers should be able to conduct original investigations, to test their own ideas, and be able to understand the relationship between their work and a wider field of knowledge. Collaborative research skills enable the researcher to learn through a personal reflection of ideas and the generation of multiple perspectives through collaborative deliberation and dialogue. It increases the 
ability of the researcher to locate, gather and synthesize various perspectives, and point of views and hence widens the scope of the research. This widening of scope does not benefit the researcher only but has positive connotations for the general society as well. IT or technology skills refer to the researcher being proficient in computer and internetbased tools. Information Technology skills are different from computer skills in the sense that they teach and enable the researcher to indulge in problem solving, reasoning and complexity management (Snyder, 2004).

\section{Conclusion and Recommendations}

It can be concluded that education, at least in Pakistan's context, has been commoditized and commercialized. Majority acquire education to serve secondary purposes instead of the primary purpose of acquiring knowledge and broadening one's view of the world. Education should be knowledge-based and not degree-based. The purpose of education, especially at the postgraduate level, should be to enhance the intellectual capacities of students.

The Pakistani education system, which has been weak for more than six decades now, cannot be changed overnight, but small steps need to initiate to resolve the identified problems one at a time. Trained and qualified faculty needs to be inducted, which should not only act as facilitators to postgraduate researchers and students but also as a bridge between students and the industry. Faculty should also be willing to share their information and knowledge with students in order for knowledge to develop further on. Improved access to content and the right information and computing technology that would facilitate a postgraduate researcher to conduct a meaningful research is also needed. Basic educational background makes real difference in the quality of postgraduate researchers. It is observed that Pakistani postgraduate researchers, who have a sound educational background, fare much better when it comes to performing as a postgraduate researcher both locally and internationally, whereas those researchers whose primary and higher secondary education background has been weak, find it more difficult to cope up with the current level of postgraduate education.

An email was sent to selected respondents for the purpose of research validation of the proposed scholarship skill-set. The respondents were asked to review the model and respond to the 7 questions. The suggestions and recommendations of the respondents have been incorporated in the model. Lastly, we would like to point out that it is our responsibility as citizens of Pakistan to help reform our educational sector for generations to come as no one can help those who are unwilling to help themselves. 


\section{References}

Borgman, L. Christine (2007), Scholarship in the Digital Age: Information, Infrastructure, and the Internet, MIT Press.

Hidi Suzanne and Harackiewicz M. Judith (2000), 'Motivating the academically unmotivated: A critical issue for the 21st century', Review of Educational Research, Vol. 70, No. 2, pp. 151-179.

Hoodbhoy, Pervez (ed.) (1998) Education and the State: 50 Years of Pakistan, Oxford University Press.

Johnson, Doug, (2005) Skills for a Knowledge Worker, www.dougjohnson.com/dougwri/skills-for-the-knowledge-worker.html.

National Research Council Staff, (2002) Preparing for the Revolution: Information Technology and the Future of the Research University, Washington DC,: National Academies Press,

http://ezproxy.library.nyu.edu:6305/lib/nyulibrary/Doc?id=10038674andppg=15

Rahman, Tariq (2004), Denizens of an Alien World, Oxford University Press.

Schwartz, A. Martin, (9th April 2008), The Importance of Stupidity in Scientific Research, Journal of Cell Science 121, 1771

Snyder, Lawrence (2004), Fluency with Information Technology: Skills, Concepts and Capabilities, Pearson Education Addison-Wesley, Prentice Hall.

\section{Interviews}

Dr. Sahar Nadeem [November 4, 2008] Coordinator BS Social Sciences (SZABIST), Karachi, Pakistan.

Dr. Sajida Zaki [November 15, 2008] Assistant Professor NED University, Karachi, Pakistan.

Mumtaz Halepoto [November12, 2008] Urban Planning Consultant CMD, Karachi Pakistan.

Qashif Effendi [November 17, 2008] Group Head Marketing and Communication K.E.S.C., Karachi, Pakistan.

Raja Asif Manzoor [November 17, 2008] CEO Steps Ahead, Karachi Pakistan. Syed Jehangir Ali [November 14, 2008] Head of Tand OD, State Bank of Pakistan, Karachi, Pakistan. 
Syed Nawab [November 17, 2008] CEO Textila, Karachi.

\section{Email Respondents}

Dr. Meher Zaidi [April 9, 2009] PhD Scholar, London School of Economics and Political Science. 